\title{
CONTROLE INADVERTIDO PELA LOCALIZAÇÃO EM TAREFAS DE MATCHING-TO-SAMPLE COM INDIVÍDUOS COM TRANSTORNO DO ESPECTRO AUTISTA.
}

\section{INADVERTENT ESTABLISHMENT OF CONTROL BY LOCATION IN MATCHING-TO-SAMPLE TASKS IN INDIVIDUALS WITH AUTISM SPECTRUM DISORDER.}

\author{
CÁSSIA LEAL DA HORA - ORCID 0000-0001-5029-9600 \\ Paradigma - Centro de Clências e Tecnologia do Comportamento, Brasil \\ PAULA DEBERT - ORCID 0000-0002-2519-2569 \\ UNIVERSIDADE DE SÃO PAULOE \\ instituto Nacional de Ciência e Tecnologia sobre Comportamento, Cognição e Ensino, Brasil \\ DANIELle L. LAFRANCE - ORCID 0000-0001-6089-6580 \\ ENDICOTT COLLEGE, Estados UnIDOS \\ CAIO F. MIGUEL - ORCID 0000-0002-5624-6718 \\ CALIFORNIA StATE UnIVERSITY, SACRAMENTO, Estados UnidOS
}

\begin{abstract}
RESUMO
Estudos com sujeitos não humanos mostraram que o estabelecimento de controle inadvertido pela localização pode prejudicar a aquisição de relações condicionais em procedimentos de matching-to-sample (MTS). O objetivo do Experimento 1 foi verificar se esse fenômeno ocorreria com indivíduos com Transtorno do Espectro Autista (TEA) em sessões de treino com MTS sem procedimentos adicionais que pudessem favorecer a aquisição, tais como procedimentos de esvanecimento, dicas e correção. Todos os três participantes mostraram controle pela localização mesmo depois de completar um mínimo de 50 sessões de treino com MTS arbitrário com dois estímulos de comparação. Um segundo estudo foi realizado para verificar se o controle pela localização ocorreria durante o procedimento MTS usando três estímulos comparação. Dezesseis participantes completaram duas sessões de treino. Os resultados deste estudo indicam que 13 desses participantes exibiram controle pela localização no início do treino. Em conjunto, os resultados de ambos os experimentos indicam que o controle pela localização pode prejudicar a aquisição de relações condicionais em indivíduos com TEA, utilizando procedimentos MTS, sem procedimentos adicionais de aprendizagem sem erro, como apresentação ou esvanecimento de dicas.
\end{abstract}

Palavras-chave: controle por localização, matching-to-sample, discriminação condicional, Transtorno do Espectro Autista.

ABSTRACT
Studies with non-human subjects have shown that inadvertent establishment of control by location can interfere with the acquisition of conditional relations in matching-to-sample (MTS) procedures. The purpose of Experiment 1 was to verify whether this phenomenon would occur with individuals with Autism Spectrum Disorder (ASD) in training sessions with MTS, without fading, prompting, and correction procedures that could improve training efficacy. All three participants showed control by location even after completing a minimum of 50 training sessions of arbitrary MTS with two comparison stimuli. A second study was conducted to verify if control by location would occur during MTS procedures using three comparison stimuli. Sixteen participants completed two training sessions. Results of this study indicate that 13 of these participants exhibited control by location at the beginning of training. Taken together, the results of both experiments indicate that, in the absence of errorless learning procedures, such as stimulus fading, control by location can interfere with the acquisition of conditional relations taught via MTS procedures in individuals with ASD.

Key words: control by location, matching-to-sample, conditional discrimination, Autism Spectrum Disorder

Esta pesquisa foi financiada com bolsa de mestrado pela Fundação de Amparo à Pesquisa do Estado de São Paulo (processo: 06/05628-4) e é parte do programa científico do Instituto Nacional de Ciência e Tecnologia sobre Comportamento, Cognição e Ensino e teve financiamento do CNPq (processo: 465686/2014-1) e da Fapesp (processo: 2014/50909-8). Correspondência referente a este artigo deve ser endereçada a Cássia Leal da Hora (cassiadahora@paradigmaac.org) ou Paula Debert (pdebert@uol.com.br).

DOI. 10.18542/rebac.v14i1.7155 
In simple simultaneous discrimination tasks, two or more stimuli are presented concurrently in different locations, and responding to one of these stimuli is followed by reinforcement. Control by location (or location bias) is established when responses are emitted toward one single location, regardless of the stimuli presented in that location (e.g., Sidman \& Stoddard, 1967). Studies conducted by Sidman and Stoddard (1967), Bickel, Richmond, Bell, and Brown (1986), and McIlvane, Kledaras, Callahan, and Dube (2002), with participants with developmental disabilities, show that difficulties in producing discriminative control may be attributed to the inadvertent establishment of control by location in a simple simultaneous discrimination task.

Difficulties in establishing conditional discrimination performances using matching-to-sample (MTS) procedures may also be attributed to the inadvertent establishment of control by location. In a MTS task, two or more stimuli are presented successively in each trial (sample stimulus) and two or more stimuli are presented simultaneously in the same trial (comparison stimuli). Selecting the stimulus arbitrarily designated as the correct comparison in relation to the sample is followed by reinforcement. The establishment of control by location is evidenced when participants respond based upon location, rather than selecting the correct comparison, regardless of its location (e.g., selections consistently occur on the left of a stimulus array). These kinds of performances have been extensively demonstrated in studies using MTS procedure with nonhuman animals (e. g., Iversen, Sidman, \& Carrigan, 1986; Sidman, 1992; Kangas \& Branch, 2008).

Gomes, Varella, and De Souza (2010) and McLay, Sutherland, Church, and Tyler-Merrick (2013) showed that most of the experimental studies using MTS to produce emergent conditional relations with participants with Autism Spectrum Disorder (ASD) reported difficulties in establishing performances involving arbitrary conditional discriminations. However, neither of these studies clearly described training performances in a way that these difficulties could be attributed to the establishment of inadvertent control by location. To our knowledge, there is only one study with participants with ASD that attributed these difficulties to the establishment of control by location during identity MTS tasks (Gomes $\&$ de Souza, 2008).

Even though there are no data showing that control by location is produced when arbitrary MTS procedures are used with participants with developmental disabilities, most lessons introduced early in teaching include additional procedures (e.g., prompting, fading, error correction procedures, etc.) to avoid the inadvertent establishment of control by location.

The purpose of the present study was to verify if control by location would be established when individuals diagnosed with an ASD were exposed to arbitrary MTS tasks without any additional procedures such as prompting or fading. If control by location could not be established, the use of additional procedures may not be required.
In Experiment 1, individuals diagnosed with ASD were exposed to an arbitrary MTS procedure with two comparison stimuli. Errorless learning procedures were not used in this experiment, to verify whether control by location would be established and maintained despite further training.

Since control by location was established early in training in Experiment 1, in Experiment 2, an arbitrary MTS procedure with three comparison stimuli was used across only two training blocks to determine whether increasing the number of comparisons would prevent the establishment of control by location to decrease the likelihood of selection by exclusion. It should be noted, however, that all MTS procedures should present three comparison stimuli to avoid what Sidman (1987) described as "selection by exclusion."

\section{EXPERIMENT 1 METHOD}

\section{Participants}

The current study was approved by the Ethics Committee from the University of São Paulo and meets the standards established by Resolution CNS No. 466/12 (and its complements), dealing with the ethical aspects of research involving human subjects.

In both experiments, the main criterion for selecting the participants was a diagnosis of Autism Spectrum Disorder (ASD), regardless of any prior experience with MTS or behavior analytic interventions. Three individuals diagnosed with ASD participated in Experiment 1. Listener skills of all participants were tested using the Receptive Peabody Picture Vocabulary Test PPVT, Form III-A.

Table 1: Experiment 1 - General Participant Characteristics.

\begin{tabular}{ccccc}
\hline & $\begin{array}{c}\text { Chronological } \\
\text { Age (in years } \\
\text { and months) }\end{array}$ & $\begin{array}{c}\text { PPVT (in } \\
\text { years and } \\
\text { months) }\end{array}$ & Sex & $\begin{array}{c}\text { Previous } \\
\text { Experience } \\
\text { with MTS }\end{array}$ \\
\hline P1 & 7.2 & 5.7 & M & Y \\
P2 & 8.6 & 4.9 & M & N \\
P3 & 8.2 & 7.0 & M & Y \\
\hline
\end{tabular}

Table 1 shows participants' chronological age, test age obtained with the PPVT, gender, and history with MTS procedures prior to participation in the current experiment. All participants were male, and their chronological age ranged from 7-8 years of age. Only one participant $(\mathrm{P} 2)$ did not have any previous exposure to MTS procedures.

\section{Setting and Materials}

Data were collected in a room in participants' homes measuring approximately $3 \mathrm{~m} \times 5 \mathrm{~m}$. The materials used included: participant-selected toys, games, and snacks. Matching-to-sample trials were presented manually using a $29.7 \mathrm{~cm}$ by $21 \mathrm{~cm}$ spiral notebook with white A4 paper. Each page included a sample stimulus at the top and two comparison stimuli at the bottom for selection (placed in the left and right bottom corners). The 
comparison stimulus was covered with a small cardboard flap, and uncovered after the participant touched the sample stimulus (i.e., an observing response). As each trial was completed, the experimenter flipped the trial page and the next page became visible to the participant. The stimuli were $4.79 \mathrm{~cm}$ by $4.79 \mathrm{~cm}$. The two-choice MTS procedure was chosen to teach fewer conditional relations and to maintain simplicity for participants that did not have a preexperimental history with the MTS procedure.

\section{Procedure}

Prior to training, a multiple stimulus without replacement (MSWO) preference assessment was conducted (DeLeon \& Iwata, 1996) to identify items that could be used as reinforcers. Seven items previously identified through parent interviews were presented side-by-side on a table (approximately $10 \mathrm{~cm}$ apart from one another). The instruction "Pick one," was then presented. Following selection of one of the items, participants were permitted to manipulate the item for approximately $5 \mathrm{~s}$ or to consume it. None of the items, whether tangible or edible, were returned or replaced in the stimulus array. In each trial, the position of the remaining items was randomly rotated and the instruction "Pick one," was repeated. This procedure was followed either until each of the items was chosen, or until participants did not select an item within $15 \mathrm{~s}$ of the initial instruction.

All participants were trained to select comparison stimuli utilizing a conditional discrimination procedure (MTS task) to identify the possible establishment of control by location. The MTS procedure included six arbitrary stimuli designated for descriptive purposes as $\mathrm{X} 1$ ', $\mathrm{X} 2$ ', Y1', Y2', Z1' and Z2' (see Figure 1). The task consisted of training arbitrary relations between stimuli $\mathrm{X}$ and $\mathrm{Y}$, and $\mathrm{Y}$ and $\mathrm{Z}$. All stimuli measured $5.56 \mathrm{~cm}$ in height by $5.88 \mathrm{~cm}$ in length. Each session consisted of three blocks of eight trials (i.e., for a total of 24). Following completion of a training session, participants were provided a short break (approximately 3 to 5 minutes) during which they were allowed to engage in a self-selected activity (e.g., reading books or playing with toys).

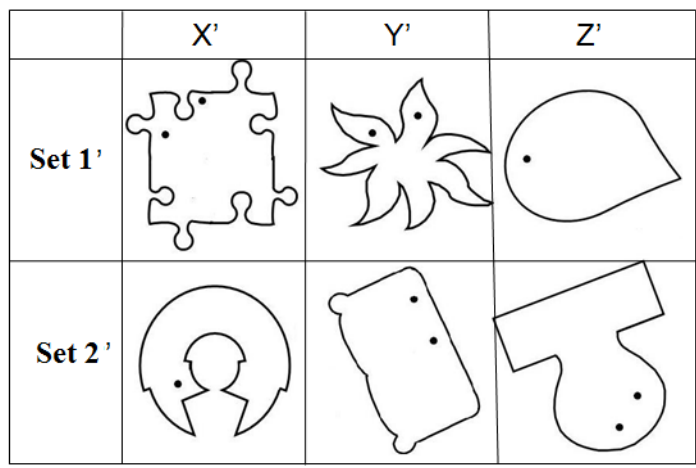

Figure 1. Arbitrary Stimuli Used For Training In Experiment 1, with Experimental Designations (X1, X2, Y1, Y2, Z1 and Z2). Stimuli were created using Paint Version 6.0 for Windows software and are an adaptation of compound stimuli used in Devany, Hayes, and Nelson (1986).

Before each trial, participants were instructed to touch the sample stimulus. After the participant touched the sample stimulus (observing response), the instruction, "What goes with this one?" was presented and the comparison stimuli, until then covered with a card, were immediately revealed while the sample stimulus remained present.

In all trials, selection responses were considered correct if the comparison stimulus selected matched the sample stimulus, and incorrect if the comparison stimulus did not match the sample. Correct responses were followed by praise, and presentation of a previously identified reinforcer, and presentation of the next trial. Two seconds elapsed between trials (i.e., intertrial interval; ITI). Incorrect responses did not result in programmed consequences and were followed by the next trial.

Table 2 depicts all types of trials presented in a block, the stimuli correlated with reinforcement ("correct" presented in bold) or "incorrect" (not bolded) for each trial, and the respective locations in which stimuli were presented.

Table 2: Trial Types Presented In a Single MTS Training Block In Experiment 1.

\begin{tabular}{|c|c|c|}
\hline \multirow{2}{*}{ Sample } & \multicolumn{2}{|c|}{ Training $X^{\prime} Y^{\prime}$ and $Y^{\prime} Z^{\prime}$} \\
\hline & Left & Right \\
\hline \multirow{2}{*}{$\mathrm{X} 1{ }^{\prime}$} & Y1' & Y'’ \\
\hline & $\mathrm{Y} 2$ ' & Y1' \\
\hline \multirow{2}{*}{$\mathrm{X} 2$ ' } & Y2' & $\mathrm{Y}^{\prime}$ \\
\hline & Y1' & Y2' \\
\hline \multirow{2}{*}{ Y1' } & $\mathbf{Z 1}$ & Z2' \\
\hline & $\mathrm{Z} 2^{\prime}$ & $\mathbf{Z 1}$ \\
\hline \multirow{2}{*}{ Y2' } & $\mathbf{Z 2}$ & $\mathrm{Z} 1^{\prime}$ \\
\hline & $\mathrm{Z} 1{ }^{\prime}$ & $\mathbf{Z 2}$ \\
\hline
\end{tabular}

Accurate performance with MTS tasks including two comparison stimuli could constitute $50 \%$ responding in each of the two locations since the "correct" comparison stimulus was presented an equal number of times in each location. High percentage scores obtained for one location, however, would indicate the establishment of control by location. Participants 1 and 3 were exposed to 61 sessions and Participant 2 was exposed to 54 sessions. The number of sessions was independent of performance and depended upon participants' availability.

\section{RESULTS AND DISCUSSION}

Figure 2 depicts the percentage of responses emitted to comparisons presented on the left in each MTS training session for participants 1, 2 and 3. Scores falling around $50 \%$ (see range marked by the two dotted lines) indicate no evidence of control by location.

In the first three sessions for P1, the percentage of responses to stimuli presented on the left oscillated between $38 \%$ and $50 \%$. In the fourth session, scores increased to approximately $70 \%$, which would be indicative of control by the left location. Further, the percentage of responses to stimuli presented on the left remained higher than the percentage of responses to stimuli presented on the right in all training sessions (46 out of a total of 61 sessions completed, or $75 \%$ of sessions). Therefore, P1 selected the stimulus presented on the left in most of the trial sessions. 


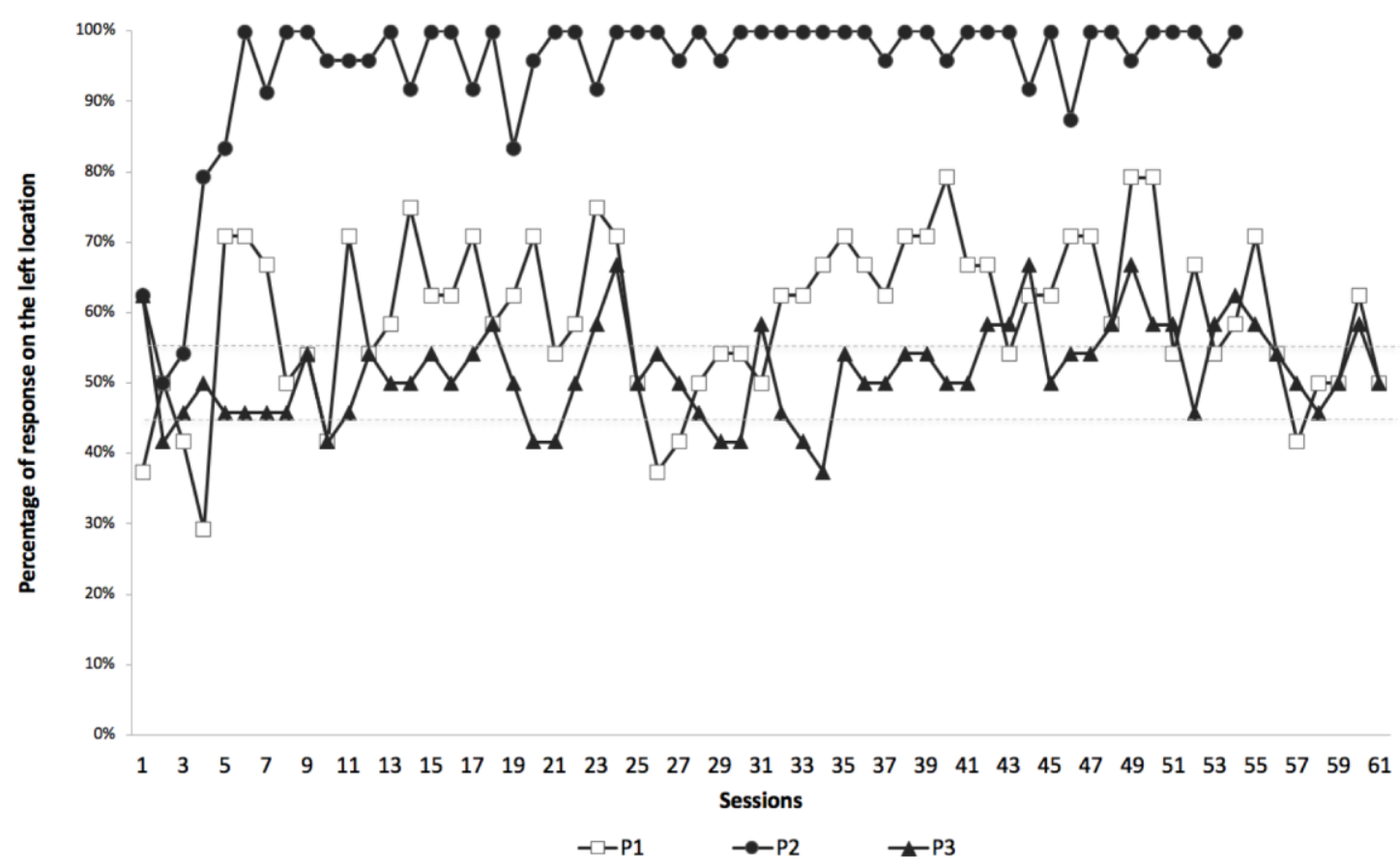

Figure 2. Percentage of response on the left location for P1, P2, and P3 in Experiment 1.

Figure 2 shows that $\mathrm{P} 2$ selected stimuli on the left in $60 \%$ of trials during the first session and in $50 \%$ of trials during the second session. Starting in the third session, the percentage of responses to the left progressively and steadily increased, until P2 responded almost exclusively to stimuli on the left. In fact, P2 selected the stimulus presented on the left in $94 \%$ of sessions. This performance is clearly indicative of control by location.

Unlike P1 and P2, P3's percentage of responses to stimuli presented on the left was very close to $50 \%$ in most sessions (37 of 61), indicating that P3 selected stimuli in both locations without indication of clear preference. However, data yielding the percentage of trials that P3 alternated from choosing the comparison presented on the right location to the left location on the next trial and vice-versa seems to indicate that control by location may have been established (see Figure 3).

Figure 3 shows the percentage of trials in each session in which P3 changed the location of his selection response in relation to the location of the comparison selected on previous trials across training sessions. In most sessions (33 of 61 in total), the percentage of trials in which P3 changed the location of selection responses exceeded $70 \%$ (see data points above the highest dashed line). In 16 sessions, the percentage of trials in which P3 switched location was above $83 \%$. In sessions, 15,19 , and 41 , the percentage of trials increased to $92 \%$. These results indicate that, during the majority of trials, P3 alternated the location of his selection responses from trial to trial. This performance may also indicate the inadvertent establishment of control by location.

The results show that control by location was clearly observed in P1 and P2's performances. P2's scores show a higher percentage of selection responses occurrring on the left. It should be noted that P2 was the only participant who had no prior experience with MTS. It is possible that previous experiences with MTS procedures could affect control by location and this is likely a good question for future research endeavors.

In training, control by location occurs when responses are emitted proportionally to a higher degree to one single location, independent of the comparison stimuli presented (e.g., Sidman \& Stoddard, 1967). P3 did not allocate his responding to any particular position. However, he did select a comparison in a different location from trial to trial, which could be interpreted as control by location. For example, if P3 selected a stimulus comparison on the left position, on the next trial, he would select the stimulus presented on the right (and viceversa).The results obtained with the three participants in Experiment 1 indicate that control by location persists even after several additional sessions of MTS training, a finding similar to studies conducted with animals (e.g., Iversen, 1997; Iversen, Sidman, \& Carrigan, 1986; Kangas \& Branch, 2008; Sidman, 1992) and similar to what was observed by Gomes and De Souza (2008) with persons with ASD during identity MTS procedures. 


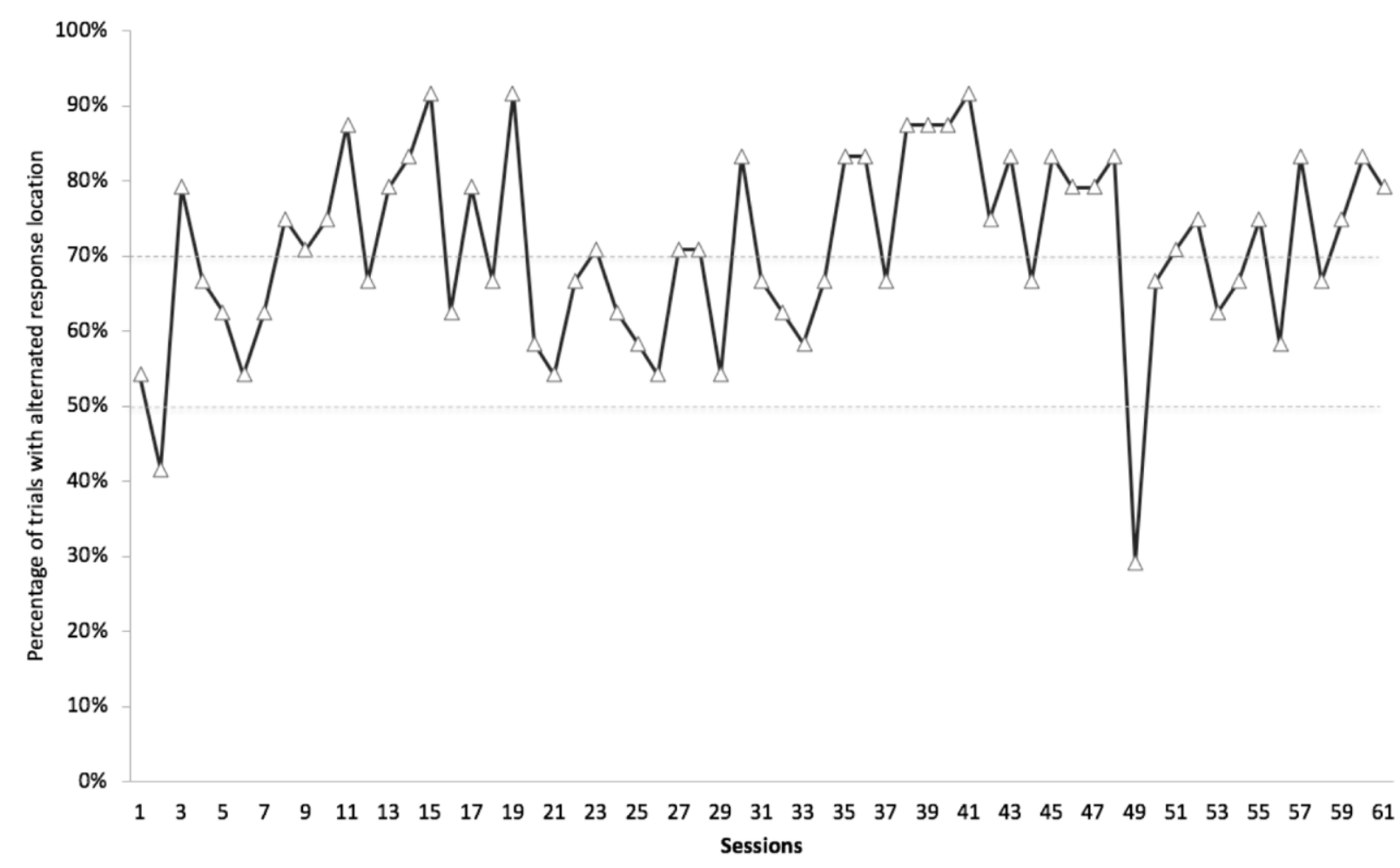

Figure 3: Percentage of trials in which P3 alternated response location throughout training sessions.

Considering that increasing the number of comparison stimuli may prevent the establishment and persistence of control by location, and considering that MTS procedures should be conducted with three comparison stimuli to prevent the establishment of selection by exclusion (Sidman, 1987), a second experiment was conducted to verify if a MTS procedure with three comparison stimuli could prevent the establishment of control by location.

\section{Participants}

\section{EXPERIMENT 2 METHOD}

Sixteen individuals diagnosed with ASD participated in the experiment. Only one of them (P16) also participated in Experiment 1, where he was referred to as P1. All participants were recruited from educational organizations serving individuals with developmental disabilities. Listener skills of all participants were tested using the Receptive Peabody Picture Vocabulary Test PPVT, Form III-A. This research was approved by the Ethics Committee from the University of São Paulo.

Participants' general characteristics are presented in Table 3, which shows their chronological age, age obtained on the PPVT, and prior history with MTS procedures. Half of the participants were male, and half were female. Participants' chronological ages ranged from 4-29 years and the majority of participants had already been exposed to MTS tasks, generally as a function of intervention based on the principles of Applied Behavior Analysis (ABA) either prior to, or during the current experiment.

\section{Setting and Materials}

Data collection was conducted in a familiar room in each participant's educational setting or home and was approximately $3 \mathrm{~m} \times 5 \mathrm{~m}$ in dimension. Materials were the same as in Experiment 1.

\section{Procedure}

Sessions consisted of the presentation of an MTS procedure that included nine arbitrary stimuli designated (for descriptive purposes) as X1, X2, X3, Y1, Y2, Y3, Z1, $\mathrm{Z} 2$ and Z3. Stimuli were selected from available images on the MTS 11.6.4 software (Dube \& Hiris, 1999). The stimuli used were modified from Experiment 1 for which P1 (previously included in Experiment 1) learned conditional relations. Additionally, a third comparison stimulus was included in every trial (instead of two comparison stimuli, as in Experiment 1). The three-choice matching procedure was chosen to prevent conditional discriminations from coming under the control of an incorrect comparison (Green, 2001; Johnson \& Sidman, 1993) and to determine whether an increased number of comparisons could interfere with the establishment of control by location. All stimuli used measured $4.79 \mathrm{~cm}$ in height by 4.79 in length. 
Table 3: Experiment 2 - General Participant Characteristics.

\begin{tabular}{ccccc}
\hline Chronological & $\begin{array}{c}\text { Corresponding } \\
\text { Age (in years } \\
\text { and months) }\end{array}$ & $\begin{array}{c}\text { And months) on } \\
\text { the PPVT }\end{array}$ & Sex & $\begin{array}{c}\text { Previous } \\
\text { Experience } \\
\text { with MTS }\end{array}$ \\
\hline P1 & 6.4 & 6.10 & F & Y \\
P2 & 10.3 & 12.5 & F & Y \\
P3 & 11.0 & 4.3 & M & Y \\
P4 & 9.1 & 2.7 & F & Y \\
P5 & 9.0 & 6.3 & M & Y \\
P6 & 19.9 & 2.7 & M & N \\
P7 & 13.3 & 4.3 & F & N \\
P8 & 29.2 & 5.0 & F & N \\
P9 & 6.10 & 4.9 & F & Y \\
P10 & 4.6 & 3.0 & M & Y \\
P11 & 4.7 & 2.9 & M & Y \\
P12 & 8.2 & 6.1 & M & Y \\
P13 & 28.11 & 6.5 & M & N \\
P14 & 7.11 & 4.1 & F & Y \\
P15 & 8.4 & 4.9 & F & Y \\
P16 & 7.2 & 5.7 & M & Y \\
\hline & & & &
\end{tabular}

All materials were presented in the same manner as in Experiment 1, and the same instructions were used. In each trial during training sessions, a sample stimulus was presented at the top, center of the page, and three comparison stimuli were presented on the lower part of the sheet (i.e., in the bottom left corner, bottom center, and bottom right corner). As with MTS training in Experiment 1 , comparison stimuli were covered by a small cardboard flap at the beginning of a trial. Following an observing response (participants were required to touch the sample stimulus), the card was removed, and the comparison stimuli appeared while the sample was concealed with an index card. A trial ended following the emission of a selection response.

Each block consisted of 18 trials. Table 4 depicts all trial types presented in a block, the stimuli correlated with reinforcement ("correct" - presented in bold) or "incorrect" (not bolded) for each trial, and the respective locations in which stimuli were presented.

Consequences for correct and incorrect responses were the same as in Experiment 1. Training was terminated following the completion of a total of two blocks (a total of 36 trials), regardless of performance. Once most of the participants exhibiting control by location in these initial trials, there was no justification to prolong the training phase.

During MTS tasks with three comparison stimuli, each stimulus was presented approximately in each of the three possible locations across $33 \%$ of trials (i.e., correct comparisons were presented an equal number of times in all three locations). High percentage scores related to one location indicated the inadvertent establishment of control by location.
Table 4: Trial Types Presented In A Single MTS Training Block In Experiment 2.

\begin{tabular}{cccc}
\hline \multirow{2}{*}{ Sample } & \multicolumn{3}{c}{ Training XY and YZ } \\
\cline { 2 - 4 } & Left & Center & Right \\
\hline \multirow{2}{*}{ X1 } & Y1 & Y2 & Y3 \\
& Y3 & Y1 & Y2 \\
& Y2 & Y3 & Y1 \\
\hline \multirow{2}{*}{ X2 } & Y2 & Y1 & Y3 \\
& Y3 & Y2 & Y1 \\
& Y1 & Y3 & Y2 \\
\hline \multirow{2}{*}{ X3 } & Y3 & Y1 & Y2 \\
& Y2 & Y3 & Y1 \\
& Y1 & Y2 & Y3 \\
\hline \multirow{2}{*}{ Y1 } & Z1 & Z2 & Z3 \\
& Z3 & Z1 & Z2 \\
& Z2 & Z3 & Z1 \\
\hline \multirow{2}{*}{ Y2 } & Z2 & Z1 & Z3 \\
& Z3 & Z2 & Z1 \\
& Z1 & Z3 & Z2 \\
\hline \multirow{2}{*}{ Y3 } & Z3 & Z2 & Z1 \\
& Z1 & Z3 & Z2 \\
& Z2 & Z1 & Z3 \\
\hline
\end{tabular}

\section{RESULTS AND DISCUSSION}

Table 5 shows the percentage of responses emitted toward each of the locations, as well as the total number of times participants selected comparison stimuli in each location (left, center, or right) across 36 trials (within parentheses).

As depicted in Table 5, of the 16 participants evaluated, 13 demonstrated performance indicative of location bias (i.e., selection of comparison stimuli in a single, unique location occurring in greater than $66 \%$ of trials) - see bolded numbers. Only three participants did not exhibit performance indicative of control by location (i.e., P1, P12, and P13), another three responded under control of the right or left positions, and another $10(62 \%)$ responded under control of the central position. These results seem to indicate that most participants responded to stimuli in the central position. This finding is similar to the results obtained by Gomes and de Souza (2008), in which the central position also was chosen by the majority of participants $(85 \%$ and $93 \%$ in training blocks 2 and 3, respectively). Future studies could investigate whether there are differences in effort as related to allocation of responses to these different positions. None of the participant showed the "alternating" pattern demonstrated by P3 in Experiment 1 .

It is worth noting that control by location was identified both in the performance of participants who had no previous experience with MTS tasks and those who had already passed training of this type at some time during the period in which they were exposed to behavior analytic intervention programs. Among the participants that did not demonstrate control by location, only P1 and P12 had already been exposed to some type of training with the MTS procedure, while P13 had not. 
Table 5: Percentage of selection responses in each location in Experiment 2.

\begin{tabular}{cccc}
\hline & $\begin{array}{c}\text { \% Selection } \\
\text { Responses to } \\
\text { Left }\end{array}$ & $\begin{array}{c}\text { \% Selection } \\
\text { Responses to } \\
\text { Center }\end{array}$ & $\begin{array}{c}\text { \% Selection } \\
\text { Responses to } \\
\text { Right }\end{array}$ \\
\hline P1 & $13.9(05 / 36)$ & $47.2(17 / 36)$ & $38.9(14 / 36)$ \\
P2 & $2.8(01 / 36)$ & $\mathbf{9 1 . 7}(\mathbf{3 3} / 36)$ & $5.5(02 / 36)$ \\
P3 & $0(00 / 36)$ & $\mathbf{1 0 0 . 0}(\mathbf{3 6} / 36)$ & $0(00 / 36)$ \\
P4 & $13.9(05 / 36)$ & $\mathbf{6 6 . 7}(\mathbf{2 4 / 3 6})$ & $19.4(07 / 36)$ \\
P5 & $\mathbf{1 0 0 . 0 ( 3 6 / 3 6 )}$ & $0(00 / 36)$ & $0(00 / 36)$ \\
P6 & $0(00 / 36)$ & $\mathbf{1 0 0 . 0}(\mathbf{3 6 / 3 6})$ & $0(00 / 36)$ \\
P7 & $22.2(08 / 36)$ & $\mathbf{7 5 . 0}(\mathbf{2 7 / 3 6})$ & $2.8(01 / 36)$ \\
P8 & $0(00 / 36)$ & $\mathbf{1 0 0 . 0}(\mathbf{3 6 / 3 6})$ & $0(00 / 36)$ \\
P9 & $16.7(06 / 36)$ & $\mathbf{7 7 . 8}(\mathbf{2 8} / 36)$ & $5.5(02 / 36)$ \\
P10 & $8.3(03 / 36)$ & $\mathbf{8 6 . 1}(\mathbf{3 1} / 36)$ & $5.5(02 / 36)$ \\
P11 & $\mathbf{9 4 . 4 ( 3 4 / 3 6 )}$ & $5.5(02 / 36)$ & $0(00 / 36)$ \\
P12 & $33.3(12 / 36)$ & $44.4(16 / 36)$ & $22.2(08 / 36)$ \\
P13 & $16.7(06 / 36)$ & $36.1(13 / 36)$ & $47.2(17 / 36)$ \\
P14 & $8.3(03 / 36)$ & $\mathbf{8 8 . 9}(\mathbf{3 2} / 36)$ & $2.8(01 / 36)$ \\
P15 & $22.2(08 / 36)$ & $\mathbf{6 9 . 4 ( 2 5 / 3 6 )}$ & $8.3(03 / 36)$ \\
P16 & $13.9(05 / 36)$ & $16.7(06 / 36)$ & $\mathbf{6 9 . 4}(\mathbf{2 5} / 36)$ \\
\hline
\end{tabular}

The results of this experiment indicate that, in conditional discrimination tasks, the use of procedures in which responses may be allocated to more than one location (as is the case with MTS), may favor the inadvertent establishment of control by location in individuals diagnosed with ASD. These results corroborate those of studies conducted with non-human animals in which inadvertent control by location appeared to be a critical variable affecting the acquisition of conditional relations (Iversen, Sidman, \& Carrigan, 1986; Sidman, 1992).

The results of Experiment 2 also indicate that control by location can be established at the beginning of training (i.e., within 36 trials). Therefore, procedures that avoid the establishment of control by location (for example, successive MTS or go/no-go procedures) could be substituted for MTS procedures when the goal is to establish conditional discriminations in individuals diagnosed with ASD.

\section{GENERAL DISCUSSION}

Results obtained in both Experiments 1 and 2 indicated that 15 of the 18 participants demonstrated performance indicative of location bias following training with a MTS task. Therefore, individuals diagnosed with ASD may show control by location when exposed to MTS tasks without the use of errorless learning procedures. These findings are consistent with what has been demonstrated in studies with non-human subjects (e.g., Iversen, Sidman \& Carrigan, 1986; Sidman, 1992) and with persons with ASD exposed to identity MTS procedure (Gomes \& De Souza, 2008).

When comparing the findings across experiments, it appears that increasing the number of comparison stimuli (from two to three) seemed to facilitate the establishment of control by location early in training. In Experiment 1 (with two comparisons), control by location was shown to occur only in the third or fourth session (around 72 trials), while in Experiment 2 (with three comparisons), control by location was shown to occur in the first session for most participants. Therefore, it is probably the case that increasing the number of comparison stimuli interferes with the establishment of conditional discriminations in individuals diagnosed with autism. It is also important to note that, although it is expected that control established by non-relevant sources can be extinguished during training, and that control by the relevant sources would also be reinforced throughout sessions (McIlvane \& Dube, 2003; Serna et. al., 2000), when considering individuals with ASD, it is essential to plan contingencies that promote efficiency (i.e., Green, 2001; Gomes, Varella \& de Souza, 2010).

In addition, teaching configurations that avoid the prompting and fading requirement are important (although they often facilitate learning), since there is evidence in the staff training literature showing challenges related to the implementation of prompting and fading procedures (Jahr, 1998). Jahr (1998) points to a clear need to develop technology to teach practitioners to use such strategies in a truly effective way, avoiding prompt dependence. This is also important to avoid the deleterious effects of exposure to errors and inaccessibility to reinforcers (i.e. Stoddard, de Rose, \& McIlvane, 1986; Terrace, 1963).

Future studies should increase the number of trials with three comparisons to evaluate if control by location would be maintained and also compare procedures with two and three (or more) comparisons, for the purposes of replication, as well as to further our understanding of the effects of these types of procedural differences. Additionally, future investigations should seek to manipulate several of the parameters considered to be critical in teaching this type of performance, such as delaying the presentation of stimuli, using different types of stimuli, varying the task presentation and the types of tasks (intermodal) presented, as well as the use of errorless learning procedures (prompting and fading).

In summary, results obtained in the current study are also in line with the current existing literature that demonstrates the inadvertent establishment of control by location with individuals with developmental disabilities in simple simultaneous discrimination tasks (e.g., Bickel et al., 1986; McIlvane et al., 2002; Sidman \& Stoddard, 1967).

Control by location can be established early in training (Experiment 2) and be maintained despite additional training (Experiment 1). Considering that errorless learning procedures could lengthen the duration of training (e.g., Kangas \& Branch, 2008), procedures different from MTS such as single-key procedures (e.g., Debert, Matos, \& McIlvane, 2007; Frank \& Wasserman, 2005; Lantaya, Miguel, Howland, LaFrance, \& Page, 2018; Zentall \& Hogan, 1975) should be considered to establish conditional discriminations with individuals diagnosed with ASD. 
It is important to highlight that the present experiments aimed to simply document the development of inadvertent control by location within a standard MTS task preparation. Thus, the findings obtained only demonstrate that control by location commonly occurs in individuals diagnosed with autism. It remains critically necessary to conduct further investigations to evaluate procedures that are a good alternative to MTS and that will help avoid the establishment of control by location when teaching conditional discriminations to individuals diagnosed with ASD.

\section{DECLARATION OF CONFLICT OF INTEREST}

The authors declare that there is no conflict of interest regarding the publication of this article.

\section{CONTRIBUTION OF EACH AUTHOR}

We certify that all authors have participated sufficiently in the work to make public their responsibility for the content

\section{COPYRIGHT}

This is an open article and may be freely reproduced, distributed, transmitted or modified by anyone provided it is used for non-commercial purposes. The work is made available under the Creative Commons 4.0 BY-NC license.

\section{(cc) $\mathrm{BY}-\mathrm{NO}$}

\section{REFERENCES}

Bickel, K. W., Richmond, G., Bell, J., \& Brown, K. (1986). A microanalysis of the controlling stimulusresponse relations engendered during the assessment of stimulus overselectivity. The Psychological Record, 36, 225-238. DOI: https://doi.org/10.1007/BF03394943

Debert, P., Matos, M.A., \& McIlvane, W. (2007). Conditional relations with compound abstract stimuli using a go/no-go procedure. Journal of the Experimental Analysis of Behavior, 87, 89-96. DOI: https://doi.org/10.1901/jeab.2007.46-05

DeLeon, I. G., \& Iwata, B. A. (1996). Evaluation of a multiple-stimulus presentation format for assessing reinforcer preferences. Journal of Applied Behavior Analysis, 29, 519-532. DOI: https://doi.org/10.1901/jaba.1996.29-519

Devany, J. M., Hayes, S. C., \& Nelson, R. O. (1986). Equivalence class formation in language-able and language-disabled children. Journal of the Experimental Analysis of Behavior, 46, 243-257. DOI: https://doi.org/10.1901/jeab.1986.46-243

Dube, W. V., \& Hiris, E. J. (1999). MTS software documentation. Waltham, MA: E. K. Shriver Center.

Frank, A., \& Wasserman, E. (2005). Associative symmetry in the pigeon after successive matching-tosample training. Journal of the Experimental Analysis of Behavior, 84, 147-165. DOI: https://doi.org/10.1901/jeab.2005.115-04

Gomes, C. \& de Souza, D. (2008). Desempenho de pessoas com autismo em tarefas de emparelhamento com o modelo por identidade: efeitos da organização dos estímulos. Psicologia: Reflexão e Crítica, 21(3), 418-429. DOI: https://dx.doi.org/10.1590/S010279722008000300010

Gomes, C., Varella, A., \& de Souza D., (2010). Equivalência de Estímulos e Autismo: Uma Revisão de Estudos Empíricos. Psicologia: Teoria $e$ Pesquisa. 26 (4), pp. 729-737

Green, G. (2001). Behavior analytic instruction for learners with autism: Advances in stimulus control technology. Focus on Autism and Other Developmental Disabilities, 16, 72-85. DOI: https://doi.org/10.1177/108835760101600203

Iversen, I.H. (1997). Matching-to-sample performance in rats: a case of mistaken identity? Journal of the Experimental Analysis of Behavior, 68, 27 45. DOI: http://dx.doi.org/10.1901/jeab.1997.68-27

Iversen, I. H., Sidman, M, \& Carrigan, P. (1986). Stimulus definition in conditional discriminations. Journal of the Experimental Analysis of Behavior, 45, 297 - 304. DOI: https://doi.org/10.1901/jeab.1986.45-297

Kangas, B. D., \& Branch M.N. (2008) Empirical validation of a procedure to correct position and stimulus biases in matching-to-sample. Journal of the Experimental Analysis of Behavior, 90, 103-112. DOI: https://dx.doi.org/10.1901/jeab.2008.90-103

Jahr, E. (1998). Current Issues in Staff Training 1. Research in Developmental Disabilities, 19(1), 7387. DOI: https://doi.org/10.1016/S08914222(97)00030-9

Johnson, C., \& Sidman, M. (1993). Conditional discrimination and equivalence relations: control by negative stimuli. Journal of the Experimental Analysis of Behavior, 59, 333-347. DOI: https://doi.org/10.1901/jeab.1993.59-333

Lantaya, C. A., Miguel, C. F., Howland, T. G., LaFrance, D. L. and Page, S. V. (2018). An evaluation of a visual-visual successive matching- to- sample procedure to establish equivalence classes in adults. Journal of the Experimental Analysis of Behavior, 109, 533-550. doi:10.1002/jeab.326

McIlvane, W. J., \& Dube, W. V. (2003). Stimulus control topography coherence theory: Foundations and extensions. The Behavior Analyst, 26(2), 195-213. DOI: https://doi.org/10.1007/BF03392076

McIlvane, W. J., Kledaras, J. B., Callahan, T. C., \& Dube, W. V. (2002). High-probability stimulus control topographies with delayed $\mathrm{S}+$ onset in a simultaneous discrimination procedure. Journal of the Experimental Analysis of Behavior, 77, 189-198.

McLay, K. L., Sutherland, D., Church, J., \& TylerMerrick. (2013). The formation of equivalence classes in individuals with autism spectrum disorder: A review of the literature. Research in Autism Spectrum Disorders, 7, 418-431. doi.org/10.1016/j.rasd.2012.11.002. DOI: doi.org/10.1016/j.rasd.2012.11.002.

Serna, R. W., McIlvane W. J., Lionello-DeNolf, K. M., Barros, R. S., \& Dube, W. V. (2000). Teoria de Coerência de Topografias de Controle de Estímulos na Aprendizagem Discriminativa: da pesquisa básica e 
Teoria à Aplicação. Em M. M. C. Hübner \& M. Marinotti (Orgs.), Análise do Comportamento para a Educação: Contribuições Recentes (pp. 253- 284). Campinas: ESETec

Sidman, M., \& Stoddard, L. T. (1967). The effectiveness of fading in programming a simultaneous form discrimination for retarded children. Journal of the Experimental Analysis of Behavior, 10, 3-15. DOI: https://doi.org/10.1901/jeab.1967.10-3

Sidman, M. (1987). Two choices are not enough. The Behavior Analyst, 22, 11-18.

Sidman, M. (1992). Adventitious control by the location of comparison stimuli in conditional discriminations. Journal of the Experimental Analysis of Behavior, 58, 173 - 182. DOI: https://doi.org/10.1901/jeab.1992.58173

Stoddard, L. T., de Rose, J. C., \& McIlvane, W. J. (1986). Observações curiosas acerca do desempenho deficiente após a ocorrência de erros. Psicologia, 12,1-18.

Zentall, T. R., \& Hogan, D. E. (1975). Concept learning in the pigeon: Transfer to new matching and nonmatching stimuli. American Journal of Psychology, 88, 233-244. DOI: http://dx.doi.org/10.2307/1421593

Submetido em: 05/05/2018 Aceito em: 10/11/2018 